\title{
Identificação dos fatores que afetam a ruptura de estoque utilizando análise de agrupamentos
}

\author{
Fernando Henrique Oliveira de Aguiara, Mauro Sampaio ${ }^{\mathrm{b} *}$ \\ afhaguiar@pucsp.br, PUC-SP, Brasil \\ b*msampaio@fei.edu.br, FEl, Brasil
}

\begin{abstract}
Resumo
0 trabalho se propôs a identificar as principais causas da ruptura de estoque por meio de uma análise de dados históricos da operação de um grande varejista que atua no Brasil. Este estudo foi suportado por técnicas de análise de agrupamento. 0 trabalho revelou que algumas causas da ruptura de estoque podem ser identificadas pela simples análise do banco de dados dos varejistas, contribuindo para tomadas de decisões gerenciais.
\end{abstract}

Palavras-chave

Ruptura de estoque. Varejo. Estoque. Logística. Análise de agrupamento.

\section{Introdução}

0 tema ruptura de estoque é cada vez mais reconhecido como um problema crítico no varejo (CORSTEN; GRUEN, 2003; GRANT; FERNIE, 2008). Nesta pesquisa, a ruptura de estoque é definida como um evento onde um varejista experimenta uma demanda por um item, porém ele não está disponível para venda. 0 primeiro estudo de ruptura de estoque foi realizado por Peckham (1963) e relatou taxas de ruptura de estoque de 8,5\%. Estudos mais recentes (CORSTEN; GRUEN, 2003) apontam para uma taxa de ruptura de estoque mundial em torno de 8,3\%. 0 nível relatado por Peckham (1963) é similar ao de Corsten e Gruen (2003). Apesar de todos os esforços de melhoria dos níveis de serviços logísticos dos últimos 60 anos, o nível de ruptura de estoque permanece elevado.

Durante esse período, as principais publicações na área focalizaram duas questões centrais. A primeira tinha como objetivo identificar as causas da ruptura de estoque e a segunda investigar o comportamento dos consumidores frente à ruptura de estoque. Constata-se que a literatura é rica em estudos sobre a segunda vertente, pois existem mais de mil artigos publicados. Quanto à primeira vertente, é carente em avaliar as causas da ruptura de estoque, pois há apenas 19 artigos publicados identificados nos últimos 60 anos
(MARQUI; ALCÂNTARA; CHRISTOPHER, 2010), fato esse que representa uma oportunidade de pesquisa.

Os problemas gerados pela ruptura de estoque vão além da perda de venda do item. Uma variedade de custos ocultos emerge: o cliente pode não retornar à loja, o cliente experimenta produtos da concorrência e pode não retornar, promoções podem não ser efetivas. Na perspectiva de supply chain, a ruptura de estoque distorce a previsão de demanda, erros resultam em investimentos exagerados e desnecessários em estoque e/ou em perdas de receita.

Tanto varejistas como fabricantes gostariam de identificar e mapear as causas de ruptura de estoque de suas respectivas cadeias de suprimento, pois a redução de sua ocorrência pode aumentar em até 5\% as receitas do varejista (GRUEN; CORSTEN; BHARADWAJ, 2002). Apesar da atratividade, poucos estudos até o momento se dedicaram a investigar a ruptura de estoque em países em desenvolvimento como o Brasil.

0 objetivo desta pesquisa foi investigar os níveis de ruptura de um item de elevado giro de estoque em um importante varejista do mercado brasileiro e identificar suas possiveis causas. Os varejistas normalmente têm dificuldades para identificar as causas de ruptura de estoques e até mesmo de mensurá-la. Eles possuem 
informações em seus bancos de dados, mas pouco as exploram como fonte para melhoria de seus processos.

Em resumo, este trabalho pretende responder as seguintes questões de pesquisa: Qual o nível de ruptura de um item de elevado giro de estoque em um grande varejista do mercado brasileiro? Tomando-se como parâmetro as variáveis que podem influenciar a ruptura de estoque e a própria taxa de ruptura de estoque de um item de giro elevado verificam-se padrões de comportamento similares ou dissimilares suficientemente significativos que permitam afirmar a existência de agrupamentos naturais dentre os hipermercados do varejista?

Para atingir os objetivos da pesquisa, este texto está estruturado em cinco seções, incluindo esta introdução. A 2a seção revisa a literatura sobre ruptura de estoque. A seção 3 relata a metodologia utilizada. A $4^{\mathrm{a}}$ apresenta os resultados e a última seção apresenta as conclusões do estudo.

\section{Revisão da literatura}

0 primeiro trabalho a investigar a ruptura de estoque foi o de Peckham (1963), que alertou os varejistas e fabricantes sobre as perdas potenciais decorrentes da falta de produtos nas gôndolas, mas trata-se de uma pesquisa mais voltada para o comportamento do consumidor frente à ausência do produto.

As publicações sobre esse tema focaram em uma de duas questões amplas. A primeira questão foi a mensuração dos níveis de ruptura de estoque em lojas de varejo (foco deste trabalho) e a segunda focou o comportamento dos consumidores frente à ruptura de estoque.

A literatura de ruptura de estoque com ênfase nas causas da ruptura de estoque encontra-se no Quadro 1, após uma extensa consulta a publicações nas bases de dados da EBSCO e Proquest.

Por um período de quatro dias, Emmelhainz, Emmelhainz e Stock (1991) removeram cinco itens da prateleira de um supermercado de descontos. Eles eram os itens mais vendidos das principais marcas nas seguintes categorias: café moído, suco de laranja, pasta de dente, pasta de amendoim e molho de tomate. Consumidores foram entrevistados na fila do caixa sobre sua reação à ruptura de estoque. Os resultados foram bastante diferentes para os cinco itens de teste quando comparados a outros itens encontrados em falta nas lojas.

Chaouch (2001) analisou a importância do compartilhamento de informações de estoque e venda entre varejistas e fornecedores com objetivo de minimizar os custos da operação. Nessa pesquisa, o autor identificou que fatores importantes a serem considerados são a adequação entre o investimento em inventário, a frequência de abastecimento das lojas e as perdas esperadas com ruptura de estoques.

Gruen, Corsten e Bharadwaj (2002) realizaram uma análise bibliográfica e compilaram o resultado das análises de comportamento do consumidor e de causas de ruptura de estoque. Neste trabalho foram considerados 52 estudos que examinaram o tema, este foi o primeiro estudo a mensurar a ruptura de estoque em bases mundiais. Uma das conclusões deste estudo é que a maior parte das rupturas de estoques é gerada pela operação da loja, enquanto os maiores esforços estão focados na melhoria da operação do fornecedor.

Kaipia e Tanskanen (2003) identificaram como ponto importante para reduzir a ruptura de estoque nos varejistas o compartilhamento de informações de venda com seus fornecedores e sugeriram a implantação do VMl (estoque gerido pelo fornecedor). Neste modelo proposto, os fornecedores seriam responsáveis por monitorar os ciclos de venda e o nível de estoque dos clientes, identificando o melhor momento para realizar o abastecimento das lojas.

Gimenéz e Ventura (2003) identificaram inicialmente alguns fatores que estão diretamente relacionados com o desempenho dos varejistas, tais como redução de custos, redução de ruptura de estoques e redução de tempos de processo. Com o objetivo de melhorar a performance, esses autores entendem que é primordial melhorar a integração dos processos internos do varejista e dos processos externos com seus fornecedores.

Kucuk (2004) estudou a influência da propaganda no ponto de venda e atratividade da loja sobre a reação do consumidor frente à ruptura de estoque do refrigerante Coca-Cola. Cerca de 540 consumidores foram entrevistados em três lojas de varejo de diferentes portes na Turquia. Os resultados mostraram que a reação do consumidor frente à ruptura de estoque foi influenciada pelas variáveis independentes investigadas. Com base nos resultados, o autor recomenda que os varejistas que sofrem constantes problemas de ruptura de estoques devem investir em propaganda no ponto de venda e aumento da atratividade da loja para aumentar a fidelidade do consumidor à sua loja. Consumidores fiéis à loja tendem a substituir os produtos frente à ruptura de estoque. Já os fabricantes devem investir em fidelidade à marca, pois esses consumidores tendem a sair da loja à procura do item em falta.

Pibernik (2006) identificou em sua análise que a principal causa da ruptura de estoque está relacionada à má alocação dos produtos. E essa se estende pelos 
Aguiar, F. H. O. et al.

Identificação dos fatores... análise de agrupamentos. Production, v. 24, n. 1, p. 57-70, jan./mar. 2014

Quadro 1. Artigos sobre ruptura de estoque.

\begin{tabular}{|c|c|c|c|c|}
\hline $\mathrm{N}^{\circ}$ & Autor & Descrição & Método & Conclusão \\
\hline 1 & $\begin{array}{l}\text { Emmelhainz, Emmelhainz e } \\
\text { Stock (1991) }\end{array}$ & $\begin{array}{l}\text { ldentificar o comportamento do } \\
\text { consumidor após a remoção de itens } \\
\text { das gôndolas }\end{array}$ & $\begin{array}{l}\text { Experimento de } \\
\text { campo }\end{array}$ & $\begin{array}{l}\text { Sugere que os varejistas podem identificar mecanismos } \\
\text { para aumentar a substituição dos itens em ruptura de } \\
\text { estoque }\end{array}$ \\
\hline 2 & Chaouch (2001) & $\begin{array}{l}\text { Identificar ações para mitigar ruptura } \\
\text { de estoques no varejo }\end{array}$ & $\begin{array}{l}\text { Análise } \\
\text { exploratória }\end{array}$ & $\begin{array}{l}\text { Sugere investimento em inventário, adequação na } \\
\text { frequência de entrega dos fornecedores e mensuração } \\
\text { das perdas com ruptura de estoque }\end{array}$ \\
\hline 3 & $\begin{array}{l}\text { Gruen, Corsten e } \\
\text { Bharadwaj (2002) }\end{array}$ & $\begin{array}{l}\text { Analisar os artigos acadêmicos (mais } \\
\text { de 50) com objetivo de identificar as } \\
\text { causas de ruptura de estoque }\end{array}$ & Análise de dados & $\begin{array}{l}\text { Foi o primeiro estudo a mensurar a ruptura de estoques } \\
\text { em bases mundiais }\end{array}$ \\
\hline 4 & Corsten e Gruen (2003) & $\begin{array}{l}\text { Identificar as causas da ruptura de } \\
\text { estoque em um grande varejista }\end{array}$ & $\begin{array}{c}\text { Análise } \\
\text { exploratória }\end{array}$ & $\begin{array}{l}\text { ldentificou que a maior parte das rupturas de estoques é } \\
\text { causada por erros de processos da loja }\end{array}$ \\
\hline 5 & Kaipia e Tanskanen (2003) & $\begin{array}{l}\text { Identificar os benefícios de terceirizar } \\
\text { para os fornecedores a responsabilidade } \\
\text { de repor o estoque dos varejistas }\end{array}$ & $\begin{array}{l}\text { Experimento de } \\
\text { campo }\end{array}$ & $\begin{array}{l}\text { Propõe um modelo de abastecimento terceirizado, } \\
\text { onde o fornecedor realiza a gestão de estoque dos } \\
\text { varejistas de algumas categorias e é responsável pelo } \\
\text { abastecimento (foco itens não core) }\end{array}$ \\
\hline 6 & Gimenéz e Ventura (2003) & $\begin{array}{l}\text { Investigar os efeitos da cooperação } \\
\text { entre as empresas na melhoria do } \\
\text { desempenho }\end{array}$ & $\begin{array}{l}\text { Análise } \\
\text { exploratória }\end{array}$ & $\begin{array}{l}\text { ldentificou que quando as empresas cooperam, elas } \\
\text { atingem melhores níveis de integração de processo e } \\
\text { melhoram o desempenho }\end{array}$ \\
\hline 7 & Kucuk (2004) & $\begin{array}{l}\text { Identificar ações gerenciais para reduzir } \\
\text { os custos com ruptura de estoque }\end{array}$ & $\begin{array}{l}\text { Análise } \\
\text { exploratória }\end{array}$ & $\begin{array}{l}\text { ldentificou a importância de se ter um bom sortimento } \\
\text { de produtos para melhorar a taxa de substituição no } \\
\text { caso de ruptura de estoque e investir em ações de } \\
\text { marketing para criar fidelidade do consumidor à loja e } \\
\text { à marca }\end{array}$ \\
\hline 8 & Pibernik (2006) & $\begin{array}{l}\text { Estudar a importância da gestão da } \\
\text { ruptura de estoque sob a perspectiva } \\
\text { do fornecedor }\end{array}$ & $\begin{array}{l}\text { Análise } \\
\text { exploratória }\end{array}$ & $\begin{array}{l}\text { ldentificou que a partir de um compartilhamento de } \\
\text { informações, os fornecedores deveriam ser capazes de se } \\
\text { antecipar à ocorrência de ruptura de estoque, tomando } \\
\text { decisões de pré-alocação de produtos }\end{array}$ \\
\hline 9 & $\begin{array}{l}\text { Van Woensel, Van Donselaar e } \\
\text { Broekmeulen (2007) }\end{array}$ & $\begin{array}{l}\text { Identificar as causas da ruptura de } \\
\text { estoque no varejo }\end{array}$ & $\begin{array}{l}\text { Análise } \\
\text { exploratória }\end{array}$ & $\begin{array}{l}\text { ldentificou o relacionamento entre inventário, processos } \\
\text { de reposição, disponibilidade, nível de serviço e taxas de } \\
\text { desperdício para itens perecíveis }\end{array}$ \\
\hline 10 & Grant e Fernie (2008) & $\begin{array}{l}\text { Analisar as causas de ruptura de } \\
\text { estoque em um varejista não alimentar }\end{array}$ & $\begin{array}{l}\text { Análise } \\
\text { exploratória }\end{array}$ & $\begin{array}{l}\text { ldentificou as causas da ruptura de estoque em dois } \\
\text { grupos, sendo elas um processo de reposição e uma } \\
\text { melhor identificação da demanda }\end{array}$ \\
\hline 11 & Hardgrave et al. (2008) & $\begin{array}{l}\text { Realizar análise para identificar os } \\
\text { benefícios do uso de RFID na gestão da } \\
\text { ruptura de estoque }\end{array}$ & $\begin{array}{l}\text { Experimento de } \\
\text { campo }\end{array}$ & $\begin{array}{l}\text { Identificou que a utilização de RFID melhora } \\
\text { os processos de abastecimento e de loja e, } \\
\text { consequentemente, reduz a taxa de ruptura de estoque }\end{array}$ \\
\hline 12 & Pramatari e Miliotis (2008) & $\begin{array}{l}\text { Analisar a importância da troca de } \\
\text { informações entre os gerentes de loja } \\
\text { do varejista e a equipe comercial dos } \\
\text { fornecedores, para redução de ruptura } \\
\text { de estoques }\end{array}$ & $\begin{array}{l}\text { Experimento de } \\
\text { campo }\end{array}$ & $\begin{array}{l}\text { Identificou a importância do compartilhamento } \\
\text { de informação entre varejistas e fornecedores para } \\
\text { aumentar a disponibilidade dos produtos }\end{array}$ \\
\hline 13 & $\begin{array}{l}\text { Waller, Tangari e } \\
\text { Williams (2008) }\end{array}$ & $\begin{array}{l}\text { Analisar o impacto das combinações } \\
\text { de reposição na ruptura de estoque } \\
\text { do varejista }\end{array}$ & $\begin{array}{l}\text { Análise } \\
\text { exploratória }\end{array}$ & $\begin{array}{l}\text { ldentificou que podem ser ajustados os tamanhos } \\
\text { das caixas enviadas pelo fornecedor para se ter maior } \\
\text { aderência com os processos de reposição de gôndola } \\
\text { ocorridos pela loja. Pode ser ajustada também a } \\
\text { frequência de abastecimento da loja, de acordo com a } \\
\text { demanda e o inventário da loja }\end{array}$ \\
\hline 14 & Morgan e Dewhurst (2008) & $\begin{array}{l}\text { Analisar a importância da sinergia na } \\
\text { cadeia de abastecimento para mitigar } \\
\text { ruptura de estoques }\end{array}$ & $\begin{array}{l}\text { Análise } \\
\text { exploratória }\end{array}$ & $\begin{array}{l}\text { ldentificou que é muito importante que os varejistas } \\
\text { monitorem os seus fornecedores com o objetivo de } \\
\text { melhorar o processo de reposição e os prazos de entrega }\end{array}$ \\
\hline 15 & Grant e Fernie (2008) & $\begin{array}{l}\text { Identificar ações que possam mitigar } \\
\text { a ocorrência de ruptura de estoque } \\
\text { nas lojas }\end{array}$ & $\begin{array}{l}\text { Análise } \\
\text { exploratória }\end{array}$ & $\begin{array}{l}\text { ldentificou, de forma geral, que o espaço de exposição } \\
\text { dos itens nas gôndolas pode ser ampliado para mitigar } \\
\text { falhas de reposição. Em complemento deve ser realizada } \\
\text { uma análise por categoria de produtos, considerando } \\
\text { lealdade, taxa de substituição e imagem para definição } \\
\text { da estratégia de inventário para cada caso }\end{array}$ \\
\hline 16 & Khalid (2008) & $\begin{array}{l}\text { Identificar as causas da ruptura de } \\
\text { estoque no varejo utilizando técnicas } \\
\text { de mineração de dados }\end{array}$ & Análise de dados & $\begin{array}{l}\text { ldentificou algumas variáveis que apresentaram } \\
\text { correlação com a ruptura de estoque e recomendou } \\
\text { algumas ações para reduzir as taxas de ruptura de } \\
\text { estoque }\end{array}$ \\
\hline 17 & Aastrup e Kotzab (2009) & $\begin{array}{l}\text { Identificar as causas da ruptura de } \\
\text { estoque para o pequeno varejista no } \\
\text { mercado dinamarquês }\end{array}$ & Análise de dados & $\begin{array}{l}\text { Segmentou as causas da ruptura de estoque em dois } \\
\text { grandes grupos: processos de loja e processos extra lojas }\end{array}$ \\
\hline 18 & $\begin{array}{l}\text { Pramatari, Evgeniou e } \\
\text { Doukidis (2009) }\end{array}$ & $\begin{array}{l}\text { ldentificar os benefícios de um modelo } \\
\text { colaborativo para redução da ruptura } \\
\text { de estoque }\end{array}$ & Análise de dados & $\begin{array}{l}\text { ldentificou a importância do compartilhamento de } \\
\text { informações entre varejistas e fornecedores para } \\
\text { melhoria do desempenho da operação }\end{array}$ \\
\hline 19 & Pero et al. (2010) & $\begin{array}{l}\text { Realizar uma análise de relação entre a } \\
\text { ruptura de estoque e algumas variáveis } \\
\text { de abastecimento }\end{array}$ & Análise de dados & $\begin{array}{l}\text { ldentificou que alguns fatores, tais como distância } \\
\text { do fornecedor, existência de fornecedor único e } \\
\text { complexidade da cadeia de abastecimento, podem } \\
\text { influenciar na gestão de ruptura de estoque }\end{array}$ \\
\hline
\end{tabular}


diferentes elos e processos da cadeia, incorrendo em falhas na alocação de pedidos, falha na priorização na alocação do abastecimento e na alocação dos produtos nas gôndolas.

Van Woensel, Van Donselaar e Broekmeulen (2007) focou sua análise no comportamento do consumidor frente à ruptura de estoque de produtos perecíveis $\mathrm{e}$ o desempenho da gestão de estoque. Nessa análise foi identificado que o comportamento do consumidor é diferente quando se compara o consumo de produtos perecíveis com não perecíveis e foi identificado como principal fator motivador de ruptura de estoque o algoritmo que gera pedidos automáticos para reposição das lojas. De acordo com o autor, os modelos matemáticos foram desenvolvidos para itens não perecíveis e devem ser reparametrizados para atender os itens perecíveis considerando as diferenças de comportamento do consumidor para cada item.

Grant e Fernie (2008) afirmam que a análise de disponibilidade de produtos deve ser realizada em conjunto com a reação do consumidor frente à ruptura de estoque (se a maior parte irá substituir, postergar ou procurar um concorrente). Ainda segundo os autores, essa análise é importante, pois o aumento da disponibilidade dos produtos implica em investimentos em tecnologia e gestão que podem não necessariamente compensar o retorno esperado em vendas. Argumenta ainda que recentemente tem aumentado o desenvolvimento de marca própria pelos varejistas em diferentes segmentos de consumo. Essa tendência no varejo aumenta ainda mais o impacto da ruptura de estoque sobre os fabricantes, pois nesse cenário a lealdade à loja/grupo varejista, se torna mais relevante do que a lealdade a uma marca específica de produtos.

Hardgrave et al. (2008), diretor do centro de pesquisas de RFID na Universidade de Arkansas, entrevistado pelo Supply Chain Management Review, revelou possuir um centro de pesquisas de $10 \mathrm{mil}$ metros quadrados para simular a realidade do varejo e aprimorar o uso do RFID. 0 autor afirma que para obter melhorias na operação do varejo é importante que a gestão seja no nível do item e que esta gestão é muito difícil se não for utilizada uma tecnologia como o RFID.

Pramatari e Miliotis (2008) focaram nas práticas de reposição e pedidos das lojas e sugeriram a utilização de uma plataforma na internet para compartilhar informações entre os varejistas e os fornecedores. Foi realizado um experimento em um grupo varejista da Grécia, onde os fornecedores ajudam o varejista nos processo de colocação de pedidos entre a loja e o CD (compartilhamento de informações) e como resultado foi identificada uma redução de 50\% nas taxas de ruptura de estoque.
Waller, Tangari e Williams (2008) identificou o impacto de diferentes configurações de embalagens/caixas na performance de ruptura de estoque e concluiu que para produtos de alto giro é recomendável que os fornecedores realizem o abastecimento em grandes caixas enquanto que para produtos de baixo giro é recomendável que o abastecimento seja realizado em embalagens menores.

Morgan e Dewhurst (2008) identificaram que o relacionamento entre comprador e fornecedor é o ponto fundamental de toda cadeia logística e propõe o monitoramento e o controle dos prazos e acordos de toda a interface desenvolvida entre varejistas e fornecedores com objetivo de melhorar o nível de serviço de entrega e consequentemente a disponibilidade de produtos nas gôndolas.

Grant e Fernie (2008) realizaram uma pesquisa em varejos não alimentares e identificaram que os varejos alimentares possuem um foco maior na gestão e mitigação de ruptura de estoques. Eles sugerem que sejam implantadas ações colaborativas entre os varejistas e seus fornecedores com o objetivo de melhorar a entrega dos produtos e, consequentemente, a sua disponibilidade nas lojas.

Khalid (2008) realizou um trabalho de dissertação de mestrado no Instituto de Tecnologia de Massachusetts onde utilizou análise multivariada de dados para identificar os fatores que oneram as taxas de ruptura de estoque para oito itens da Unilever utilizando ferramenta de VMI (gestão de inventário pelo fornecedor).

Aastrup e Kotzab (2009) realizaram uma pesquisa em varejistas independentes (que não fazem parte dos grandes conglomerados) e foram identificadas taxas maiores de ruptura de estoque se comparadas às operações das grandes redes. Foi identificado nessa pesquisa como principais fatores que oneram a disponibilidade de produtos ao consumidor o processo de colocação de pedido e a definição de demanda.

Pramatari, Evgeniou e Doukidis (2009) identificaram em sua pesquisa a importância de uma abordagem colaborativa entre o varejista e seus fornecedores com o objetivo de melhorar a disponibilidade de produtos nas lojas. No entanto, o autor acredita que esta abordagem só é possível se for mantida por uma ferramenta de compartilhamento de dados de base e plataforma web, o que requer alto investimento em tecnologia e geração de interfaces sistêmicas com diferentes empresas, tornando o cenário de implantação complexo e caro.

Pero et al. (2010) analisou o impacto das diferentes configurações de uma cadeia de abastecimento na gestão de ruptura de estoque do varejista. Nesse estudo foi identificado que as cadeias de abastecimento que 
apresentam maior número de nós em cada elo tendem a apresentar maiores índices de ruptura de estoque devido à menor dinamicidade da cadeia.

No Brasil, um dos poucos estudos de falta de estoque foi o realizado pela Divisão de Serviços de Varejo da ACNielsen Brasil em julho de 2004. A pesquisa analisou as principais causas, bem como a atitude do consumidor quando ele não encontra o produto na prateleira. Eles estudaram 528 SKUs (unidades mantidas em estoque) em 587 lojas de autosserviço com cinco ou mais check-outs - o resultado foi uma taxa de indisponibilidade de estoque de 8,0\%. 0 estudo também concluiu que as causas de ruptura de estoque eram distribuídas ao longo de toda a cadeia de abastecimento, mas que as principais oportunidades de melhoria estavam concentradas entre o centro de distribuição e as prateleiras do varejo. No entanto, como a amostra foi restrita a hipermercados nas capitais de São Paulo e Rio de Janeiro, não foi possível fazer qualquer generalização estatística.

Já a pesquisa survey de Vasconcellos e Sampaio (2009), realizada diretamente com gerentes de lojas de varejo, afirma o contrário, os fornecedores foram mencionados como os principais responsáveis pelas rupturas.

\subsection{Causas da ruptura no varejo}

As causas das rupturas são decorrentes de práticas ineficientes nas operações de loja, centro de distribuição do varejista, nas sedes do varejista ou fornecedor. Segundo Marqui, Alcântara e Christopher (2010), é possível segmentar as causas da ruptura no varejo em três grandes grupos:

- Problemas de planejamento;

- Problemas de processamento de pedido;

- Problemas de reposição.

Na Tabela 1 é possível identificar a contribuição de cada autor para as variáveis identificadas na literatura relacionada com elevada taxa de ruptura no varejo.

Ela lista as variáveis identificadas na literatura que influenciam a ruptura, porém nem todas são passíveis de serem investigadas através de uma base de dados, conforme proposta desta pesquisa. As variáveis específicas selecionadas para investigação neste trabalho estão declaradas mais à frente, na seção Metodologia.

\section{Metodologia}

Como o propósito desta pesquisa foi investigar os níveis de ruptura de um item de alto giro de um importante varejista do mercado brasileiro e identificar suas possíveis causas, um fenômeno sobre o qual o pesquisador não tem nenhum controle, a metodologia indicada por diversos autores (EISENHARDT, 1989; YIN, 2003; CAUCHICK MIGUEL et al., 2012) é o estudo de caso. 0 conhecimento disponível sobre o fenômeno de interesse é escasso.

Assim, de acordo com os parâmetros de Yin (2003), o presente estudo enquadra-se como um caso único, incorporado e do tipo explanatório, pela natureza rara de acesso do pesquisador a informações restritas de um importante varejista do mercado.

Os dados desta pesquisa foram obtidos a partir de um banco de dados de vendas e estoque de uma rede de varejo brasileira. A rede possui 113 lojas em todo o território brasileiro (hipermercados) e 10 centros de distribuição (CD). 0 produto selecionado para o estudo foi a cerveja Skol em lata de $350 \mathrm{~mL}$.

Podem-se enumerar três justificativas básicas de apoio à escolha dessa rede de varejo e o produto Skol como escolhas adequadas para a pesquisa. A primeira diz respeito ao aumento da concentração no varejo brasileiro. Portanto, uma pesquisa realizada com dados de uma das maiores redes de varejo do país permite uma generalização dos resultados maior do que um estudo concentrado em uma rede menor, com poucas lojas.

Em segundo lugar, o produto selecionado foi a cerveja em lata de $350 \mathrm{~mL}$, principal item da marca Skol, que se tornou líder de vendas no mercado brasileiro a partir de 1999 e também considerada a quarta cerveja mais vendida no mundo. Trata-se de um item de elevado giro de estoque e de importância estratégica tanto para o fabricante como para o varejista, cuja preocupação em evitar ruptura de estoque deveria ser central na estratégia de distribuição de ambas as empresas.

Em terceiro lugar, a falta de estudos feitos em países em desenvolvimento como o Brasil. Por isso, esta pesquisa oferece uma oportunidade de comparar resultados obtidos no Brasil com os de outras regiões do mundo. Em geral, os resultados foram diferentes dos encontrados em outras partes do mundo, nomeadamente na Europa e nos EUA. A investigação contribui também para identificar pontos fortes e fracos dos sistemas de distribuição do varejista investigado.

As principais fontes de dados nesta pesquisa são os dados dos pontos de venda (PDV) da cerveja Skol durante o ano de 2009, bem como dados de inventário de um grande varejista brasileiro. Os principais dados coletados foram: histórico de vendas, preços praticados e posição de estoque diário, cadastro informando as variantes logísticas utilizadas pelas lojas e pelos CDs, cadastro de fornecedores e seus endereços de entrega, 
Tabela 1. Descrição de fatores identificados por cada autor.

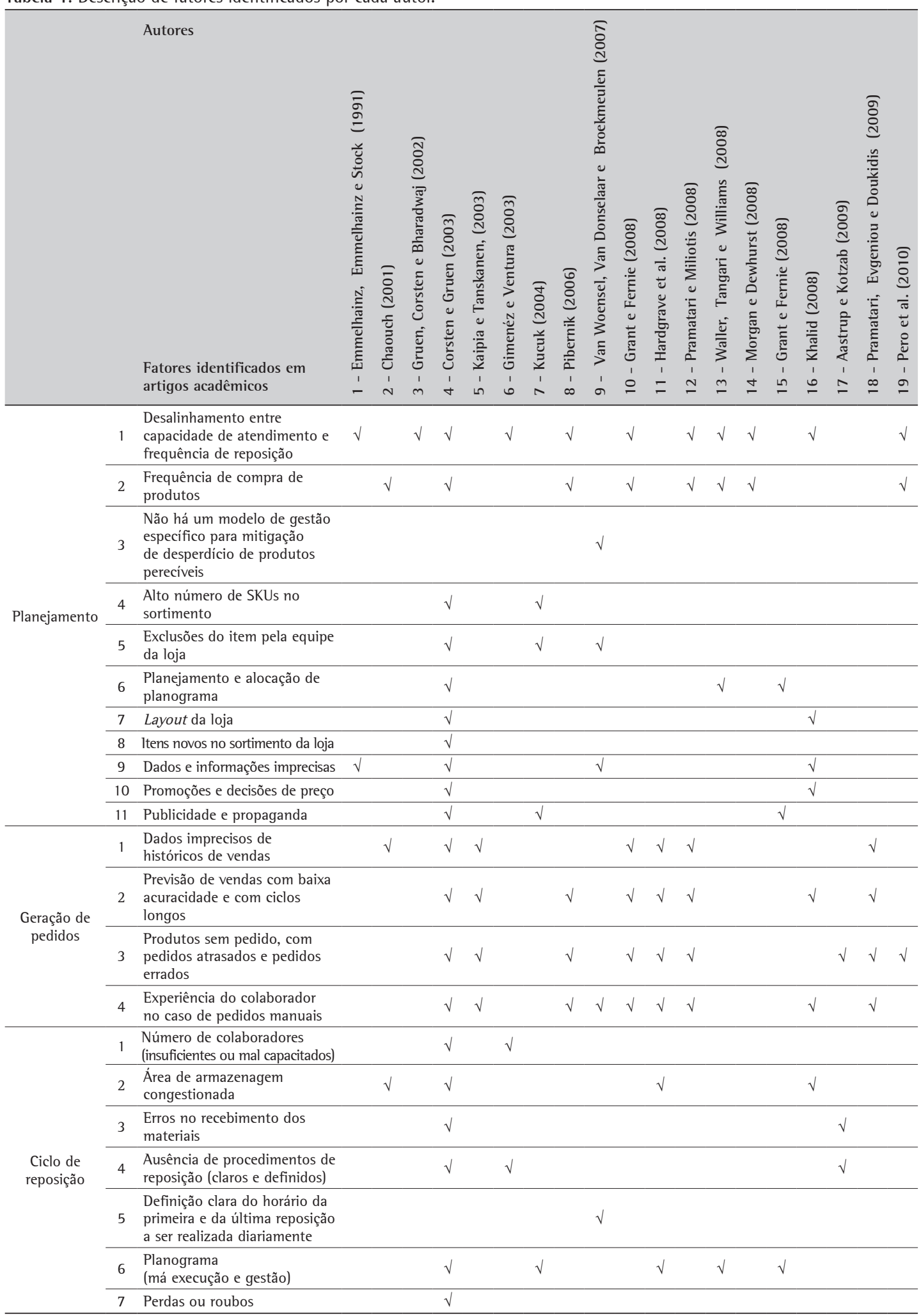


calendário de promoções, endereço das lojas e dos CDs, cadastro identificando os principais concorrentes de cada loja e um levantamento da demografia de renda dos clientes de cada loja.

Foram realizadas diversas checagens de consistência como, por exemplo: análise de gráficos de vendas e estoques individuais de todas as lojas e CDs, como mostrado na Figura 1, para a loja com menor taxa de ruptura de estoque, e na Figura 2, para a loja com pior taxa de ruptura de estoque.

Para o resultado do levantamento foi utilizado banco de dados com indicadores confiáveis de vendas, estoques, preços, entre outras informações, para 113 lojas e 2 CDs diretamente envolvidos na distribuição da cerveja Skol.

\subsection{Mensuração da taxa de ruptura de estoque anual}

A literatura apresenta várias formas tradicionais de mensuração do fenômeno ruptura de estoque: auditoria de inventário físico, análise de dados do ponto de venda (PDV), entrevistas com o consumidor e informações dos fornecedores.

Existem vantagens e desvantagens em cada uma dessas formas de mensuração: a auditoria é um método de medição confiável, entretanto é caro e consome os recursos escassos da organização. A medição dos níveis de estoque nas lojas é facilmente avaliada através de sistemas de informação. 0 problema é que existe um percentual de inconsistências, normalmente há uma diferença entre o estoque físico real e o encontrado no sistema (FISHER, 1997). A informação do consumidor é interessante, mas também não é muito confiável, pois é dependente do compromisso dos caixas para perguntar sistematicamente ao consumidor. Além disso, também existe a possibilidade da percepção de falta do consumidor ser incorreta. As informações prestadas pelos fornecedores são confiáveis, mas apenas uma pequena parcela dos itens (SKUs) de um supermercado tem repositores remunerados pelos fabricantes. A medida utilizada neste trabalho é derivada da literatura: análise de dados do ponto de venda (PDV). A análise de dados dos estoques indica a falta de estoque. Por exemplo, quando o nível de estoque para um item (SKU) em uma loja é zero, implica quase sempre em situação de ruptura de estoque. No entanto, conforme Khalid (2008), os dados de inventário no sistema não são um reflexo exato do que está disponível nas gôndolas, por razões tais como:

- 0 item está disponível nos bastidores, mas não está sendo abastecido nas gôndolas;

- Perda (roubo ou dano) do item que pode causar discrepância entre os dados do sistema e disponibilidade real de itens;

- Práticas de varejo danosas, especialmente devido ao registro de venda errado para itens semelhantes.

Para minimização desses problemas foi realizada uma redução no volume de estoque das lojas da ordem de 5\% do estoque médio, com o objetivo de corrigir as divergências existentes entre o estoque sistêmico e o estoque real. 0 valor 5\% é uma taxa média de

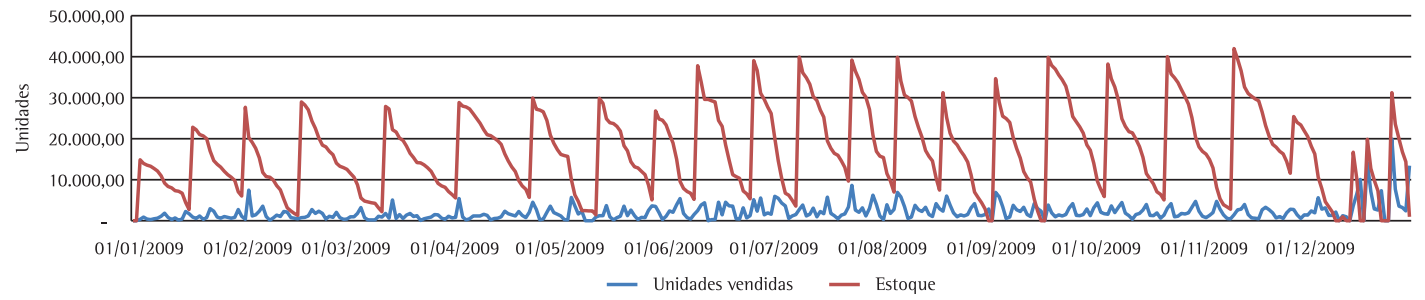

Figura 1. Gráfico de evolução diária de venda e estoque para a loja que apresentou a menor taxa de ruptura de estoque, de 2,2\% ao ano, em Manaus. Fonte: o autor.

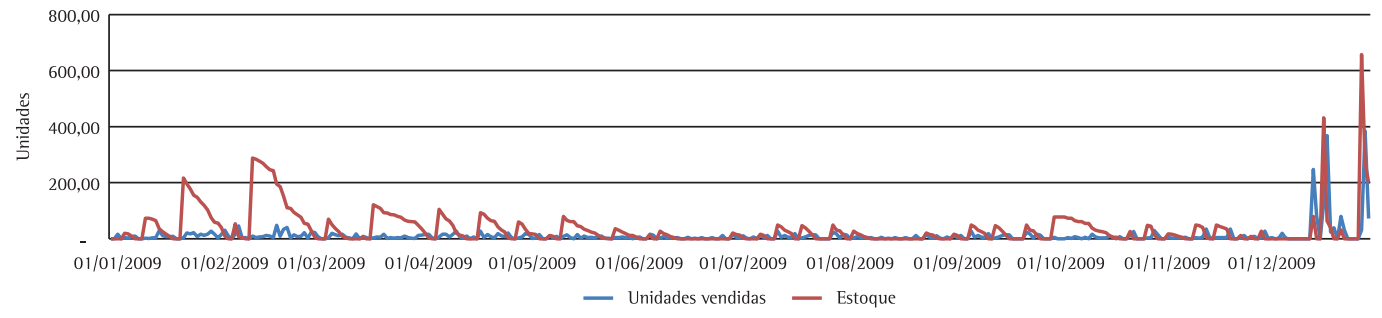

Figura 2. Gráfico de evolução diária de venda e estoque para a loja que apresentou a maior taxa de ruptura de estoque, de 26,3\% ao ano, no Rio de Janeiro. Fonte: o autor. 
erro sistêmico utilizada pelo mercado e foi validada junto ao varejista em análise para o caso de cervejas.

Apesar dos problemas identificados, a análise de dados do ponto de venda ainda continua sendo uma estimativa razoável do nível de ruptura de estoque da loja (KHALID, 2008), não é exata mas aproxima-se do real valor de ruptura de estoque. Esse procedimento é adotado por empresas tradicionais de pesquisa de mercado, como a ACNielsen (2004).

Nesta análise foi considerada ruptura de estoque o dia em que não houve venda e necessariamente não havia estoque disponível no inventário da loja, similar ao critério adotado por Khalid (2008), conforme Figura 3.

Conforme apresentado na Figura 3, foram consideradas rupturas de estoque as datas que apresentaram simultaneamente estoque zero e falta de registro de vendas, ou seja, os dias 12 e 18. Os dias 3, 11 e 17, apesar de apresentarem estoque zero, ainda apresentaram venda positiva, isto é, provavelmente, o estoque só chegou ao seu término ao final do período. Como a técnica de estoque de ponto de venda não consegue identificar essa condição, esse dia é considerado como um dia normal de vendas, sem ruptura de estoques. Já nos dias 8,14 e 21 temos situação de vendas zero, mas estoque positivo. Foi considerada essa situação como um dia normal, sem ruptura de estoque. Apesar de entender que o estoque pode estar presente na retaguarda e não no ponto de venda, gerando uma ruptura de estoque, infelizmente a técnica de análise de ruptura de estoque pelo PDV não consegue identificar essa situação. Por isso é feita a afirmação de que a técnica de análise de dados de pontos de vendas é uma estimativa da taxa de ruptura de estoque da loja mas não é uma estimativa 100\% confiável. 0 ideal seria realizar a auditoria em paralelo à análise de dados de pontos

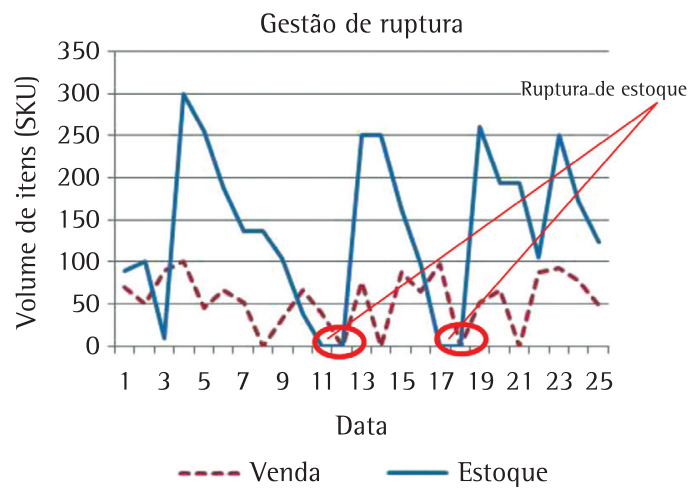

Figura 3. Modelo ilustrativo para identificação da ruptura de estoque. Fonte: adaptado de Khalid (2008). de vendas, mas a empresa pesquisada não possui essa rotina estruturada para essa análise, para esse e mesmo para outros produtos, inviabilizando-a. Trata-se, portanto, de uma limitação da pesquisa que não inviabiliza a análise atual, apenas estimula novas pesquisas nessa área de interesse, no futuro.

\subsection{Mensuração das variáveis que influenciam na taxa de ruptura de estoque}

Algumas variáveis foram selecionadas para investigação. Foram estabelecidos dois critérios para a escolha das variáveis deste estudo: (1) variáveis mencionadas anteriormente na literatura e (2) variáveis passíveis de mensuração por meio de indicadores provenientes de um banco de dados. Critérios semelhantes foram utilizados anteriormente por Khalid (2008). As variáveis de interesse foram agrupadas em três categorias: (1) características do fornecedor; (2) características do ciclo de reposição; e (3) características do mercado. Cada uma dessas características será discutida separadamente. As fontes da literatura são apresentadas na Tabela 2, enquanto os itens da escala real usada na pesquisa são apresentados na Tabela 3.

Modalidade de entrega: 0 fornecedor tem duas alternativas de entrega: ou entrega em um CD central e o varejista entrega os produtos nas lojas, ou entrega diretamente na loja. No caso estudado, a cerveja Skol é entregue nos CDs de São Paulo e do Rio Grande do Sul e repassada para $20 \%$ e $10 \%$ das lojas do varejista, respectivamente. 0 restante das entregas, 70\%, é realizado pelo fornecedor, a partir de diferentes CDs ou fábricas, diretamente nas lojas do varejo.

Distância entre o entregador e a loja: A distância entre o entregador e a loja também pode influenciar na taxa de ruptura de estoque da loja. 0 entregador pode ser um CD ou o fornecedor.

Número de entregas: A frequência de entrega por dia da semana pode influenciar a taxa de ruptura de estoque. Como a maior demanda ocorre nos fins

Tabela 2. Variáveis preditoras de ruptura de estoque.

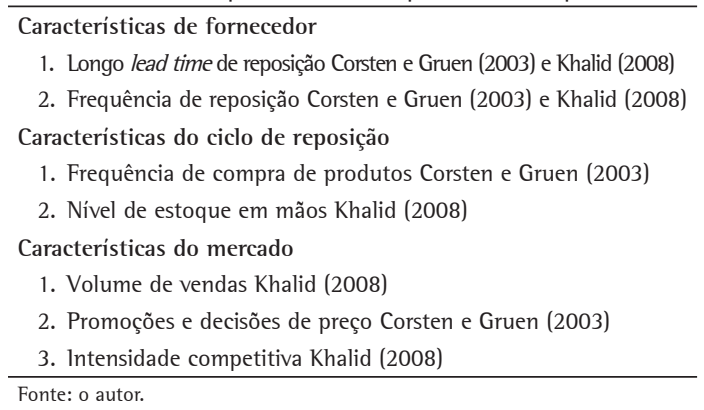


Tabela 3. Itens utilizados para medir as variáveis independentes.

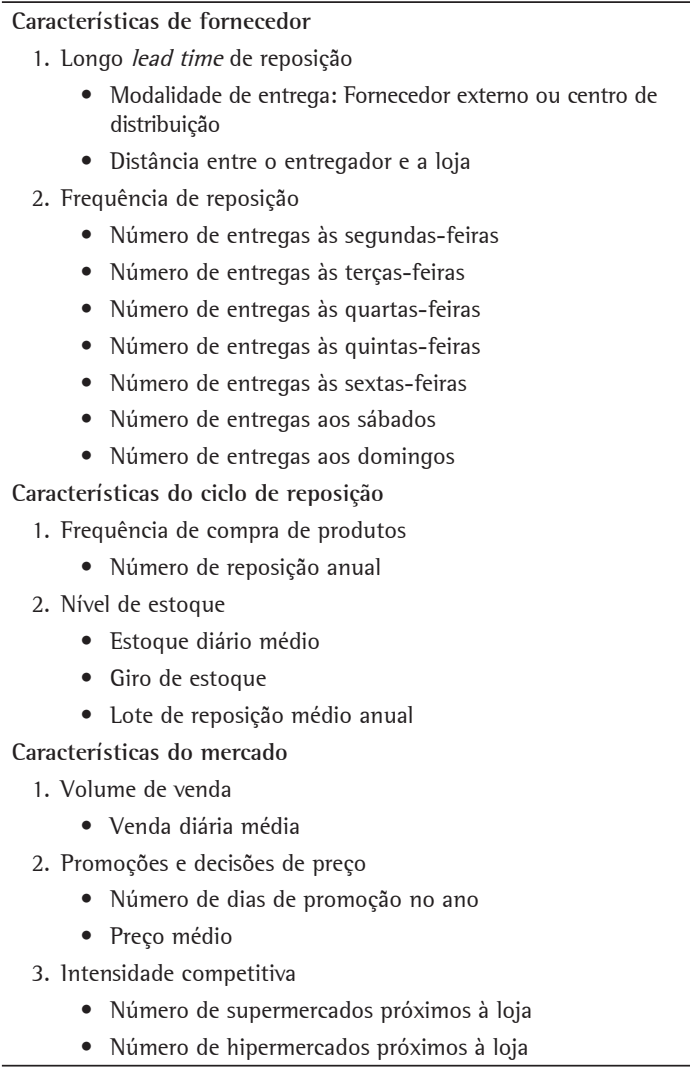

Fonte: o autor.

de semana era esperado que as entregas no início da semana provocassem mais ruptura de estoque do que nas lojas que repõem seus estoques em datas mais próximas do fim de semana.

Número de reposição anual: A frequência de compras do item cerveja Skol, foi estimada neste trabalho por meio do indicador número de reposições anuais. Existem lojas que trabalham com um padrão de reposição semanal e até lojas que fazem reposições a cada dois dias.

Nível de estoque: Os níveis de estoque foram estimados por três indicadores: estoque diário médio, giro de estoque e lote de reposição média anual. Todos os parâmetros de modelos de estoque podem afetar a taxa de ruptura de estoque, mas o giro de estoque é um indicador mais confiável de avaliação dos níveis de estoques. Ele é definido como a quantidade de vezes no ano que o estoque que a empresa mantém é vendido. Os parâmetros isolados de estoque diário médio e tamanho do lote de reposição médio são limitados, pois não levam em consideração os níveis de venda das lojas, mas mesmo assim foram testados.

Volume de vendas: Foi verificado se o volume de vendas influenciava na taxa de ruptura de estoque.
Lojas de maior volume de vendas podem ser tratadas de forma diferenciada por seus entregadores (CD ou fornecedor) e assim influenciar na taxa de ruptura de estoque da loja.

Promoções e decisões de preço: A publicidade e a propaganda possuem a missão de desenvolver a lealdade dos clientes e de criar um ambiente no qual o cliente se sinta confortável e atraído para compras. Esse ambiente pode alterar o comportamento do consumidor e incentivá-lo a realizar compras antecipadas e, consequentemente, gerar situação de ruptura de estoques. Em países desenvolvidos, as taxas de ruptura de estoques em períodos de promoção são duas vezes superiores a períodos de vendas normais. Em países em desenvolvimento como o Brasil, a influência da promoção na taxa de ruptura de estoque é desconhecida.

Intensidade competitiva: A intensidade competitiva foi mensurada em função do número de supermercados e hipermercados presentes na área de influência de cada uma das 113 lojas do varejista investigado. Como os hipermercados são maiores, foi considerada uma ponderação com peso maior para o hiper (peso 3) em relação ao supermercado (peso 1) na região da loja do varejista. Foi verificada a existência de política de abastecimento de lojas que privilegiam as que possuem um grande número de concorrentes na sua área de atuação.

\subsection{Análise de agrupamentos}

A análise de agrupamentos é uma técnica utilizada para a formação de grupos de dados similares baseada em diferentes variáveis (SHMUELI; PATEL; BRUCE, 2010). 0 principal objetivo é formar agrupamentos com dados similares. Esses agrupamentos com dados similares podem ser analisados para a identificação de padrões consistentes na amostra.

Existem dois tipos de algoritmos de agrupamentos, métodos hierárquicos e métodos não hierárquicos (FÁVERO et al., 2009). As principais diferenças entre os métodos hierárquicos e os não hierárquicos podem ser verificadas na Tabela 4.

Para esta análise foi realizada inicialmente uma análise hierárquica para identificação do número de agrupamentos, a qual foi complementada pela análise não hierárquica, com o objetivo de refinar os agrupamentos iniciais, conforme procedimento recomendado por Hair et al. (2009).

\section{Resultados}

Antes de iniciar a análise de agrupamentos foi realizada uma análise dos dados das 113 lojas para as cinco variáveis utilizadas na análise de agrupamento, 
com o objetivo de identificar possíveis outliers (FÁVERO et al., 2009). Para isso foram gerados diagramas de perfis utilizando os dados com escore padronizado Z (considerada outlier toda observação com valor absoluto superior a 3,0) - não foram encontrados outliers que necessitassem ser excluídos.

Após a avaliação da presença de outliers, foi feita uma análise da correlação entre todas as variáveis do estudo, conforme mostra a Tabela 5. 0 maior valor identificado foi de 0,489 , o que evidência uma baixa correlação relação entre as variáveis, favorecendo, portanto a aplicação da técnica de analise de agrupamentos (HAIR et al., 2009).

\subsection{Análise hierárquica}

Antes da realização da análise, os dados foram padronizados utilizando-se a transformação $z$-scores, conforme procedimento sugerido por Milligan e Cooper (1988).

Para realizar a análise hierárquica foi selecionada como medida de similaridade a distância quadrática euclidiana, pois é a medida mais comumente usada de similaridade entre dois objetos (HAIR et al., 2009).

Segundo Hair et al. (2009), para a validação das soluções de agrupamento é importante que sejam aplicados métodos de agrupamento alternativos e que sejam comparadas as soluções. Foram utilizadas duas formas de ligação para a definição do número de agrupamentos no método hierárquico:

- Ligação média (between groups): Trata a distância entre dois grupos como sendo a distância média entre todos os pares de indivíduos dos dois grupos, buscando agrupar os agregados cuja distância média é menor;

- Método de Ward: Busca agrupar os agregados que apresentam menor soma dos quadrados entre dois agrupamentos, calculada sobre todas as variáveis.

Ao realizar a análise hierárquica utilizando as ligações médias e o método de Ward, foi possivel identificar que embora tenham sido utilizados procedimentos de agrupamento diferentes para o método hierárquico, ambos apresentam a sugestão de formação de três agrupamentos.

0 resultado para o número de agrupamentos foi consistente com Lehmann (1979), o qual informa que o número apropriado de agrupamentos deve variar entre $n / 30$ até $n / 60$, sendo $n$ o tamanho da amostra. No presente caso, o intervalo de agrupamentos seria entre 1,88 e 3,76, sendo possível concluir que o número de três agrupamentos é coerente com a literatura.

\subsection{Análise não hierárquica}

A análise não hierárquica $K$-means foi realizada e através da Tabela 6 pode-se verificar que todas as variáveis apresentam diferenças significantes entre os agrupamentos (sig <0,05). Pode-se verificar também que a variável mais representativa na diferenciação dos agrupamentos foi o número de reposição às quartas $(F=80,791)$ e o giro de estoque $(F=58,098)$.

Para realizar a interpretação dos agrupamentos, segundo Hair et al. (2009), é importante a geração do perfil de agrupamentos, conforme Figura 4.

Tabela 4. Métodos de aglomeração.

\begin{tabular}{cl}
\hline Método de agrupamentos & \multicolumn{1}{c}{ Descrição } \\
\hline Método hierárquico & $\begin{array}{l}\text { Os métodos hierárquicos são também agrupamentos ou divisivos. 0 primeiro inicia com } n \text { grupos } \\
\text { que sequencialmente se associam até a formação de poucos agrupamentos. Métodos divisivos } \\
\text { funcionam no sentido oposto, iniciando com um único agrupamento e se subdividindo. }\end{array}$ \\
\hline Método não hierárquico & $\begin{array}{l}\text { Esses métodos utilizam um número de agrupamentos predefinido e o algoritmo associa os } \\
\text { valores para cada agrupamento. Um dos métodos não hierárquicos é o } k \text { - } m \text { means }\end{array}$ \\
\hline
\end{tabular}

Fonte: Fávero et al. (2009).

Tabela 5. Resultado da correlação de Pearson.

\begin{tabular}{|c|c|c|c|c|c|}
\hline & Giro de estoque & $\begin{array}{c}\% \text { de ruptura de } \\
\text { estoque - total anual }\end{array}$ & $\begin{array}{l}\text { Distância do } \\
\text { entregador até a loja }\end{array}$ & $\begin{array}{l}\text { Número de dias de } \\
\text { promoção no ano }\end{array}$ & $\begin{array}{c}\text { Número de reposição } \\
\text { às quartas }\end{array}$ \\
\hline Giro de estoque & 1 & 0,486 & $-0,037$ & $-0,205$ & 0,262 \\
\hline $\begin{array}{l}\% \text { de ruptura de } \\
\text { estoque - total anual }\end{array}$ & 0,486 & 1 & $-0,446$ & $-0,307$ & 0,341 \\
\hline $\begin{array}{l}\text { Distância do entregador } \\
\text { até a loja }\end{array}$ & $-0,037$ & $-0,446$ & 1 & $-0,183$ & $-0,128$ \\
\hline $\begin{array}{l}\text { Número de dias de } \\
\text { promoção no ano }\end{array}$ & $-0,205$ & $-0,307$ & $-0,183$ & 1 & $-0,069$ \\
\hline $\begin{array}{l}\text { Número de reposição às } \\
\text { quartas }\end{array}$ & 0,262 & 0,341 & $-0,128$ & $-0,069$ & 1 \\
\hline
\end{tabular}

Fonte: o autor. 
Tabela 6. Solução final para a análise não hierárquica de $K$-means.

\begin{tabular}{|c|c|c|c|c|c|c|c|c|c|c|c|c|}
\hline \multirow[b]{2}{*}{ Variáveis } & \multicolumn{3}{|c|}{$\begin{array}{l}\text { Centro final dos agrupamentos } \\
\text { Agrupamentos }\end{array}$} & \multicolumn{3}{|c|}{$\begin{array}{l}\text { Valores médios } \\
\text { Agrupamentos }\end{array}$} & \multicolumn{6}{|c|}{ ANOVA } \\
\hline & 1 & 2 & 3 & 1 & 2 & 3 & $\begin{array}{l}\text { Quadrado médio } \\
\text { do agrupamento }\end{array}$ & $\mathrm{df}$ & $\begin{array}{l}\text { Erro quadrático } \\
\text { médio }\end{array}$ & df & $\mathrm{F}$ & Sig. \\
\hline Giro de estoque & 1,89891 & $-0,31404$ & 0,43246 & 87,5 & 43,9 & 58,6 & 28,767 & 2 & 0,495 & 110 & 58,098 & 0,000 \\
\hline $\begin{array}{l}\text { Distância do } \\
\text { entregador até a loja }\end{array}$ & $-0,31993$ & 0,08479 & $-0,39524$ & 269,1 & 657,6 & 196,8 & 1,695 & 2 & 0,987 & 110 & 1,717 & 0,018 \\
\hline $\begin{array}{l}\text { Número de dias de } \\
\text { promoção no ano }\end{array}$ & $-0,70866$ & 0,07408 & 0,27459 & 104,8 & 149,6 & 161,1 & 3,853 & 2 & 0,948 & 110 & 4,064 & 0,020 \\
\hline $\begin{array}{l}\text { \% de ruptura de } \\
\text { estoque anual }\end{array}$ & 1,38977 & $-0,25302$ & 0,55085 & $18 \%$ & $10 \%$ & $14 \%$ & 16,833 & 2 & 0,712 & 110 & 23,637 & 0,000 \\
\hline $\begin{array}{l}\text { Número de } \\
\text { reposição às quartas }\end{array}$ & 0,19950 & $-0,28152$ & 2,55835 & 5,4 & 3,6 & 14,2 & 33,318 & 2 & 0,412 & 110 & 80,791 & 0,000 \\
\hline $\begin{array}{l}\text { Membros do } \\
\text { agrupamento }\end{array}$ & 13 & 91 & 9 & & & & & & & & & \\
\hline
\end{tabular}

Para concluir a análise de agrupamentos, foi avaliado um conjunto de variáveis adicionais não incluídas no procedimento de agrupamentos. Foi realizada a análise ANOVA para cada variável adicional, para verificar se existiam diferenças significantes entre suas médias. As variáveis que confirmaram a similaridade das médias não foram incluídas na análise de perfis, conforme mostra a Figura 5.

Após analisar todas as variáveis adicionais, apenas as variáveis da Tabela 7 apresentaram diferença significativa entre a média de cada agrupamento.

Os três agrupamentos formados apresentam diferenças consideráveis no comportamento de suas variáveis, conforme pode ser verificado na Figura 5 .

- 0 agrupamento 1 pode ser chamado de Agrupamento de lojas próximas do entregador, com alto giro de estoque e poucas promoções no ano. Esse agrupamento apresentou como principais diferenciais, se comparado com os demais, alto giro de estoque, baixo número de promoções no ano e o pior desempenho de ruptura de estoque, com uma taxa média de 18\%;

- 0 agrupamento 2 pode ser chamado de Agrupamento de lojas distantes do entregador e com baixo giro de estoque. Esse agrupamento apresentou como pontos de diferenciação, quando comparado com os demais, distância elevada entre a loja e o entregador (fornecedor externo ou interno), baixo giro de estoque, poucas reposições de estoque às quartas-feiras e a melhor taxa média de ruptura de estoque, com percentual de 10\%;

- 0 agrupamento 3 pode ser chamado de Agrupamento de lojas próximas ao entregador com altas taxas de reposição de estoque às quartas-feiras e elevado número de promoções no ano. Esse agrupamento, que apresentou resultado intermediário para giro de estoque e taxa de ruptura de estoque anual, foi composto pelas lojas que se encontram mais próximas do entregador (fornecedor interno ou externo) e as

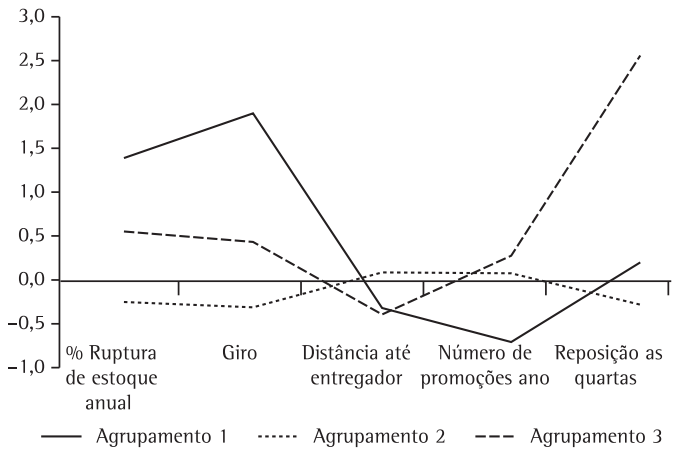

Figura 4. Perfil de agrupamento para as 5 variáveis com valores padronizados $z$-scores. Fonte: o autor.

lojas que apresentaram a maior taxa de reposição de estoque às quartas-feiras.

Analisando-se a Figura 5 é possível verificar que o agrupamento que apresenta o melhor desempenho (10\% de ruptura de estoque) é o agrupamento 2 - Agrupamento de lojas distantes do entregador e com baixo giro de estoque - e o que apresenta o pior desempenho ( $18 \%$ de ruptura de estoque) é o agrupamento 1 - Agrupamento de lojas próximas do entregador, com alto giro de estoque e poucas promoções no ano. Esse resultado pode ser considerado inesperado, pois pesquisas anteriores apresentaram resultados opostos (KHALID, 2008). Esse agrupamento apresenta 13 lojas e aparentemente o varejista e os fornecedores mantêm uma atenção maior no suprimento das lojas mais distantes. Principalmente as lojas localizadas no estado do Rio de Janeiro apresentaram resultados piores de ruptura de estoque, conforme mostra a Tabela 8 .

Os dados da Tabela 8 também revelam que os problemas maiores de ruptura de estoque estão associados a fornecedores externos, pois a própria cervejaria é responsável pelo suprimento dessas lojas, 


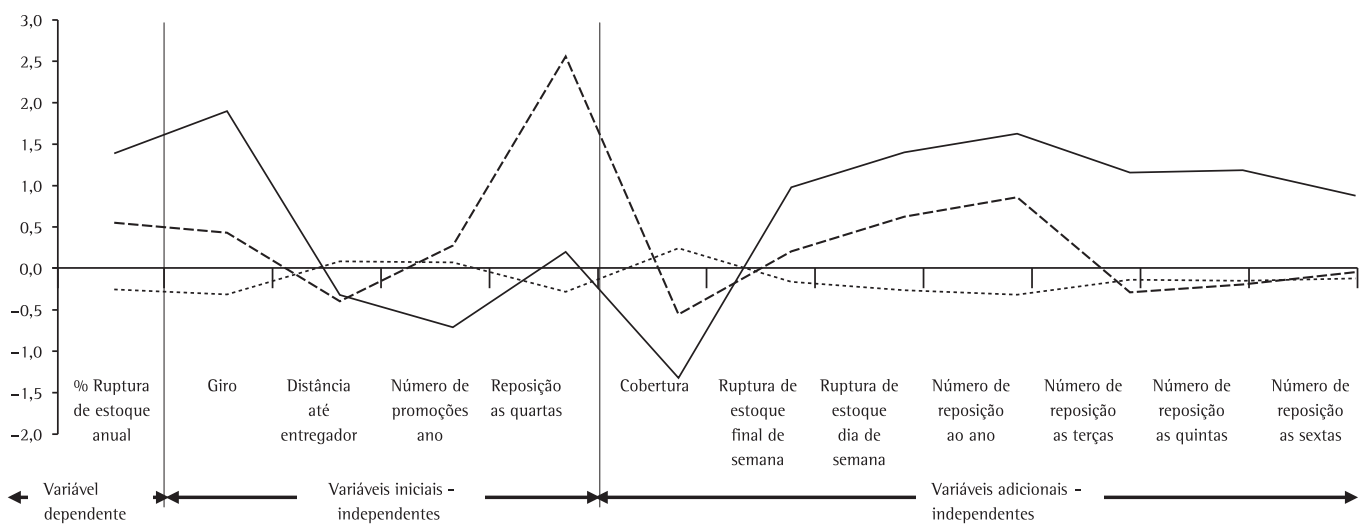

- Agrupamento 1 ....... Agrupamento 2 ---. Agrupamento 3

Figura 5. Análise de perfil incluindo variáveis adicionais. Fonte: o autor.

Tabela 7. Análise de significância para as variáveis adicionais.

\begin{tabular}{|c|c|c|}
\hline & \multicolumn{2}{|c|}{ ANOVA } \\
\hline Variável & $\mathrm{F}$ & Significância \\
\hline Cobertura & 20,945 & 0,000 \\
\hline Ruptura de estoque no final de semana & 8,617 & 0,000 \\
\hline Ruptura de estoque em dia de semana & 25,354 & 0,000 \\
\hline Número de reposições no ano & 44,598 & 0,000 \\
\hline Número de reposições na terça-feira & 11,810 & 0,000 \\
\hline Número de reposições na quinta-feira & 12,438 & 0,000 \\
\hline Número de reposições na sexta-feira & 6,191 & 0,003 \\
\hline
\end{tabular}

Fonte: 0 autor.

porém essa afirmativa é prematura, uma vez que o problema também pode ser ocasionado pela má gestão do processo de pedido do varejista.

Essa análise já possibilita um direcionamento das ações que devem ser realizadas pelo varejista.

\section{Conclusão e limitações}

Este trabalho teve como objetivo identificar os fatores que afetam a ruptura de estoque de um item de elevado giro em um varejista de grande porte do mercado brasileiro. Os resultados revelaram que as causas da ruptura de estoque não podem ser generalizadas, isto é, os resultados encontrados em países desenvolvidos não necessariamente coincidem com os problemas vivenciados no mercado brasileiro.

0 estudo revelou que o histórico de uma base de dados contém informações relevantes para a identificação dos fatores que causam a ruptura de estoque no varejo. Essas informações são úteis tanto para varejistas e fabricantes quanto para pesquisadores interessados no assunto. As lições aprendidas neste estudo são de valia, por se tratar de um varejista de destaque no mercado nacional. Foi constatado que
Tabela 8. Relação das lojas que pertencem ao agrupamento 1.

\begin{tabular}{cccc} 
Estado & $\begin{array}{c}\text { Total de lojas } \\
\text { no estado }\end{array}$ & $\begin{array}{c}\text { Taxa de ruptura de } \\
\text { estoque de cada loja (\%) }\end{array}$ & Tipo de fornecedor \\
\hline Goiás & 1 & 14,8 & Fornecedor externo \\
\hline Paraná & 1 & 12,9 & Fornecedor externo \\
\hline & 5 & 19,7 & Fornecedor externo \\
& & 21,6 & Fornecedor externo \\
Rio de & 23,3 & Fornecedor externo \\
Janeiro & & 25,2 & Fornecedor externo \\
& 1 & 26,3 & Fornecedor externo \\
\hline Rio Grande & 18,6 & CD RS \\
do Sul & 5 & 12,6 & CD SP \\
\hline & & 13,4 & CD SP \\
São Paulo & & 14,5 & CD SP \\
& & 15,3 & Fornecedor externo \\
& & 16,2 & CD SP \\
\hline
\end{tabular}

Fonte: o autor.

os varejistas possuem muitos dados, porém poucas informações para tomada de decisão gerencial.

A metodologia utilizada foi considerada satisfatória, pois permitiu, a partir de dados históricos e algumas informações de mercado, identificar fatores relevantes que influenciaram as taxas de ruptura de estoque de um item de alto giro.

Cabe agora responder as questões de pesquisa:

Qual o nível de ruptura de estoque de um item de elevado giro em um grande varejista do mercado brasileiro?

Para responder a pergunta é importante lembrar que, conforme descrito na metodologia, esta pesquisa utilizou apenas um produto e utilizou informações da base de dados de venda e de estoque para identificar a ruptura de estoque da loja.

Diante desse cenário foi verificada uma taxa média anual de ruptura de estoque para o produto cerveja Skol lata de $350 \mathrm{ml}$ de $11,5 \%$, sendo que a pior taxa anual de ruptura de estoque é de $26,3 \%$ e a melhor, 2,2\%. 


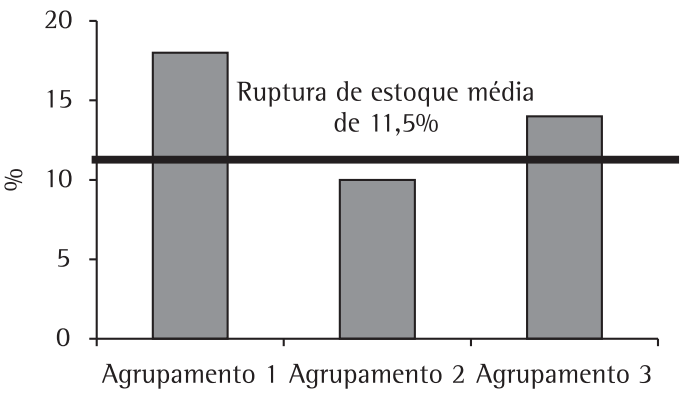

Figura 6. Taxa de ruptura de estoque para os 3 agrupamentos. Fonte: o autor.

Tomando-se como parâmetro as variáveis que podem influenciar a ruptura de estoque e a própria taxa de ruptura de estoque de um item de elevado giro, verificam-se padrões de comportamento similares ou dissimilares suficientemente significativos para permitir afirmar a existência de agrupamentos naturais dentre os hipermercados do varejista?

A análise de agrupamento comprovou a existência de três grupos de hipermercados com taxas de ruptura de estoque distintas, conforme a Figura 6. 0 agrupamento 1, denominado Agrupamento de lojas próximas do entregador, com alto giro de estoque e poucas promoções no ano, apresentou o pior desempenho, com taxa de 18\% de ruptura de estoque; 0 agrupamento 2, denominado Agrupamento de lojas distantes do entregador e com baixo giro de estoque, apresentou o melhor desempenho, com taxa de ruptura de estoque anual de 10\%.

Esse resultado foi inesperado, pois justamente as lojas mais próximas aos CDs ou fornecedores externos apresentaram os piores resultados, revelando que o problema macro para esse item não deve ser de infraestrutura logística mas sim de processo. Esses resultados conflitam com os resultados de pesquisas em países desenvolvidos. Gruen, Corsten e Bharadwaj (2002) afirmam que o principal problema de ruptura de estoque ocorre dentro da estrutura da logística do varejista, já neste caso estudado, coerente com os resultados da pesquisa de Vasconcellos e Sampaio (2009), o problema pode estar com os fornecedores.

\subsection{Limitações}

Uma das limitações deste trabalho foi a utilização de um único produto, cerveja Skol em lata de $350 \mathrm{~mL}$ : mesmo sendo considerada a quarta cerveja mais vendida no mundo e mesmo tratando-se de um item de elevado giro de estoque e de importância estratégica tanto para o varejista quanto para o fabricante, não é possível simplesmente generalizar o resultado encontrado para os demais itens comercializados em um grande varejista.
Outra limitação foi o método utilizado para estimar a taxa de ruptura de estoque, baseado em uma base de dados de venda e de estoque. Esse método não consegue identificar se o estoque que está disponível na loja se encontra na gôndola ou na área de armazenagem da própria loja, caso em que seria necessária uma auditoria física para averiguar a disponibilidade do estoque nas gôndolas, procedimento esse que não fazia parte do cotidiano do varejista.

Pode-se entender como uma terceira limitação o fato de toda a análise (113 hipermercados) ter sido efetuada em uma única rede varejista, assim algumas conclusões podem estar associadas ao modelo de gestão e aos processos vigentes no grupo empresarial, não sendo possível, dessa forma, simplesmente extrapolar os resultados para outras empresas.

A última limitação identificada é a avaliação de algumas causas possíveis de ruptura, mas não todas as listadas na revisão da literatura.

\subsection{Pesquisas futuras}

A primeira oportunidade relaciona-se à expansão da análise para um grupo maior de itens, de diferentes famílias e se possível com diferentes comportamentos esperados de consumo, dada a discrepância observada entre o case nacional e os estrangeiros congêneres.

Outra oportunidade seria realizar uma pesquisa similar em outros tipos de varejistas, tanto em hipermercados como em supermercados e redes atacadistas.

Outra pesquisa interessante seria entender o comportamento do consumidor frente à ruptura, pois essa variável influencia o dimensionamento dos estoques de segurança nas lojas.

\section{Referências}

AASTRUP, J.; KOTZAB, H. Analyzing out-of-stock in independent grocery stores: an empirical study. International Journal of Retail \& Distribution Management, v. 37, n. 9. p. 765-789, 2009. http:// dx.doi.org/10.1108/09590550910975817

ACNIELSEN. Ruptura: causas e impactos na cadeia de abastecimento e no comportamento do consumidor. In: ECR BRAZIL CONFERENCE, 2004, São Paulo. Anais.. São Paulo, 2004. Disponivel em: <http://www.ecrbrasil.com. br>. Acesso em: 11 abr. 2008.

CAUCHICK MIGUEL, P. et al. Metodologia da pesquisa em engenharia de produção e gestão de operações. Editora Campus; Abepro, 2012.

$\mathrm{CHAOUCH}$, B. A. Stock levels and delivery rates in vendormanaged inventory programs. Production and Operation Management, v. 10, p. 31-44, 2001. http://dx.doi. org/10.1111/j.1937-5956.2001.tb00066.x

CORSTEN, D.; GRUEN, T. Desperately seeking shelf availability: An examination of the extent, the causes, and the efforts to address retail out-ofstock. International Journal of Retail \& Distribution 
Management, v. 31, n. 11, p. 605-617, 2003. http:// dx.doi.org/10.1108/09590550310507731

EISENHARDT, K. M. Building theories from case study researches. Academy of Management Review, v. 14, n. 4, p. 532-550, 1989.

EMMELHAINZ, L.; EMMELHAINZ, M.; STOCK, J. Logistics implications of retail stockouts. Journal of business logistics, v. 12, p. 129-141, 1991.

FÁVERO, L. P. et al. Análise de dados: modelagem multivariada para tomada de decisões. Rio de Janeiro: Elsevier, 2009.

FISHER, M. L. What is the right Supply Chain for your product? Harward Business Review, p. 105-116, 1997.

GIMENÉZ, C.; VENTURA, E. Supply chain management as a competitive advantage in the Spanish grocery sector. The International Journal of Logistics Management, v. 14, p. 77-88, 2003. http://dx.doi. org/10.1108/09574090310806558

GRANT, D. B.; FERNIE, J. Exploring out-of-stock and onshelf availability in non-grocery, high street retailing. International Journal of Retail \& Distribution Management, v. 36, p. 661-672, 2008. http://dx.doi. org/10.1108/09590550810883496

GRUEN, T. W.; CORSTEN, D. S.; BHARADWAJ, S. Retail Stockouts: A Worldwide Examination of Extent, Causes and Consumer Responses. In: THE FOOD MARKETING INSTITUTE AND CIES - THE FOOD BUSINESS FÓRUM, 2002, Washington. Proceedings... Washington, 2002.

HARDGRAVE, B. et al. Measuring the impact of RFID on out of stock at Wal-Mart. MIS Quarterly Executive, v. 7, n. 4, 2008.

HAIR, J. F. et al. Análise multivariada de dados. São Paulo: Elsevier, 2009.

KAIPIA, R.; TANSKANEN, K. Vendor managed category management - an outsourcing solution in retailing. Journal of Purchasing \& Supply Chain, v. 9, p. 165175, 2003.

KUCUK, U. Reducing the out-of-stock costs in a developing retailing sector. Journal of International Consumer Marketing, v. 16, p. 75-104, 2004. http://dx.doi. org/10.1300/J046v16n03_05

KHALID, U. Determination of drivers of stock-out performance of retail stores using data mining techniques. 2008. Dissertation (Master of Engineering in Logistics)Massachusetts Institute of Technology, Cambridge, 2008.

LEHMANN, D. R. Market research and analysis. Homewood: Irwin, 1979.

MARQUI, A.; ALCÂNTARA, R.; CHRISTOPHER, M. Using the systematic literature review procedure to identify the root causes of out-of-stock in retail supply chains. São Carlos: UFSCar, 2010.
MILLIGAN, G. W.; COOPER, M. C. A study of standardization of variables in cluster analysis. Journal of Classification, v. 5, p. 181-204, 1988. http://dx.doi.org/10.1007/ BF01897163

MORGAN, C.; DEWHURST, A. Multiple retailer supplier performance: an exploratory investigation into using SPC techniques. International Journal of Production Economics, v. 111, p. 13-26, 2008. http://dx.doi. org/10.1016/j.ijpe.2006.11.018

PECKHAM, J. 0. The consumer speaks. Journal of Marketing, v. 27, n. 4, p. 21-26, 1963. http://dx.doi. org/10.2307/1248641

PERO, M. et al. An exploratory study of the relation between supply chain topological features and supply chain performance. International Journal of Production Economics, v. 123, n. 2, p. 266-278, 2010. http://dx.doi. org/10.1016/j.ijpe.2009.08.030

PIBERNIK, R. Managing stock-outs effectively with order fulfillment systems. Journal of manufacturing technology management, v. 17, n. 6, p. 721-736, 2006. http://dx.doi.org/10.1108/17410380610678765

PRAMATARI, K.; MILIOTIS, P. The impact of collaborative store ordering on shelf availability. Supply chain management, v. 13, p. 49-61, 2008 http://dx.doi. org/10.1108/13598540810850319

PRAMATARI, K.; EVGENIOU, T.; DOUKIDIS, G. Implementation of collaborative e-supply-chain initiatives: an initial challenging and final success case from grocery retailing. Journal of Information Technology, v. 24, p. 269281, 2009. http://dx.doi.org/10.1057/jit.2008.11

SHMUELl, G.; PATEL, N. R.; BRUCE, P. C. Data Mining For Business Intelligence. 2nd ed. Wiley, 2010.

VANWOENSEL, T. K.;VANDONSELAAR, R.; BROEKMEULEN, J. F. Consumer responses to shelf out-of-stocks of perishable products. International Journal of Physical Distribution \& Logistics Management, v. 37, n. 9, p. 704-718, 2007. http://dx.doi.org/10.1108/09600030710840822

VASCONCELLOS, L. H. R.; SAMPAIO, M. The stockouts study: an examination of the extent and the causes in the São Paulo supermarket sector. Brazilian Administration Review, v. 6, n. 3, p. 263-279, 2009. http://dx.doi. org/10.1590/S1807-76922009000300007

WALlER, M.; TANGARI, A.; WILlIAMS, B. Case pack quantity's effect on retail market share: an examination of the backroom logistics effect and the store-level fill rate effect. International Journal of Physical Distribution Management, v. 38, p. 436-451, 2008. http://dx.doi. org/10.1108/09600030810893508

YIN, R. K. Case study research, design and methods. London: Sage Publications, 2003.

\title{
Determination of drivers of stock-out performance of retail stores using cluster analyses
}

\begin{abstract}
This study proposes to identify the main causes of out of stock through a database analysis of a representative Brazilian retailer. This database analysis was supported by cluster analyses. The study found that some causes of rupture can be identified simply by analyzing the retailer's database, contributing to managerial decision making.
\end{abstract}

Keywords

Stockout. Retail. Inventory. Logistics. Cluster analyses. 